\title{
Estudo de gráficos da cinemática através do jogo batalha naval e de atividades robóticas ${ }^{+}$
}

\author{
Luiz Antonio Dworakowski ${ }^{1}$ \\ Pedro Fernando Dorneles ${ }^{1}$ \\ Ângela Maria Hartmann ${ }^{1}$ \\ Universidade Federal do Pampa \\ Bagé - RS
}

\section{Resumo}

A experiência didática descrita e analisada neste artigo foi desenvolvida em uma escola estadual do município de Candiota, RS, no formato de dois módulos didáticos, contendo atividades para a introdução ao ensino do plano cartesiano e de gráficos de Cinemática. No primeiro módulo, enfatizou-se o estudo de coordenadas cartesianas, utilizando o jogo batalha naval e a construção de um plano cartesiano no pátio da escola. No segundo módulo, abordou-se a elaboração e a interpretação de gráficos em Cinemática, com ênfase no emprego de tecnologias computacionais, fazendo uso da plataforma Arduino para construção de carrinhos automatizados e de um aparato utilizando sensor de posição. A experiência didática foi realizada à luz das orientações curriculares descritas em documentos oficiais de ensino e alicerçada na teoria de aprendizagem significativa de Ausubel. A intervenção foi desenvolvida em duas turmas de $1^{\circ}$ ano do Ensino Médio e os resultados, a partir de análises estatísticas (nível de significância estatística inferior a 0,01) e categorias qualitativas, evidenciaram que as atividades propostas constituem uma possibilidade eficaz para introdução ao estudo de gráficos, especialmente da Cinemática. Durante a intervenção, os alunos desenvolveram habilidades para localizar pontos no plano cartesiano, coletar e representar de forma adequada, em tabelas, dados de tempo e deslocamento, bem como construir gráficos do movimento. Além disso, os alunos demons-

\footnotetext{
${ }^{+}$Study of kinematics graphs through naval battle game and robotic activities

* Recebido: agosto de 2017. Aceito: julho de 2018.

${ }^{1}$ E-mails: luiz.dworak@gmail.com; pedroftd@gmail.com; angelahartmann@unipampa.edu.br
} 
traram capacidade para interpretar e analisar dados de tempo, deslocamento e velocidade constantes em gráficos do movimento uniforme e reproduzir esse movimento através de um carrinho automatizado e de um sensor de movimento.

Palavras-chave: Ensino Médio; Gráficos em Cinemática; Ensino de Física; Robótica.

\begin{abstract}
The didactic experience described and analyzed in this article was developed in a state school in the municipality of Candiota, RS, in the format of two didactic modules, containing activities for the introduction to the teaching of the Cartesian plan and Kinematic graphs. In the first module, we emphasized the study of Cartesian coordinates, using the naval battle game and the construction of a Cartesian plan in the schoolyard. In the second module, the elaboration and interpretation of graphs in Kinematics, with emphasis in the use of computational technologies, was made use of the Arduino platform for construction of automated trolleys and of an apparatus using position sensor. The didactic experience was carried out in the light of the curriculum guidelines described in official teaching documents and based on Ausubel's meaningful learning theory. The intervention was developed in two classes of 1st year of High School and the results, based on statistical analyzes (level of statistical significance less than 0.01) and qualitative categories, showed that the proposed activities constitute an effective possibility for introduction to the study of graphics, especially Kinematics. During the intervention, students developed abilities to locate points on the Cartesian plane, collect and represent appropriately, in tables, time and displacement data, as well as construct movement charts. In addition, students demonstrated ability to interpret and analyze time, velocity, and velocity data on uniform motion graphs and reproduce this movement through an automated cart and motion sensor.
\end{abstract}

Keywords: High School; Graphics in Kinematics; Physics Teaching; Robotics. 


\section{Introdução}

Um grande número de informações apresentadas através de representações visuais, como gráficos, tabelas e diagramas, está cada vez mais presente na sociedade contemporânea. Nos dias atuais, é difícil encontrar alguma área da ciência ou da tecnologia em que a construção e o estudo de gráficos não sejam necessários. Na educação escolar, o estudo da Física, em particular, tem o uso de gráficos como ferramenta básica para representar e relacionar grandezas em praticamente todos os assuntos tratados. Contrapondo-se à importância do estudo de gráficos em Cinemática, surge a grande dificuldade apresentada pelos estudantes em geral, quando necessitam construí-los ou interpretá-los.

As principais dificuldades encontradas pelos alunos para analisar a interpretação de gráficos de Cinemática segundo Beichner apud Araujo, Veit e Moreira (2004) são: a) visão de gráficos como uma fotografia do movimento; b) confusão entre altura e inclinação ou entre área/inclinação/altura; c) confusão entre variáveis cinemáticas; d) erros quanto à determinação de inclinação de linhas que não passam pela origem; e) desconhecimento do significado das áreas no gráfico abaixo das curvas cinemáticas.

A partir de estudos da literatura da área de Educação em Ciências sobre as dificuldades enfrentadas pelos estudantes da Educação Básica em interpretar e construir gráficos (ARAUJO; VEIT; MOREIRA, 2004; PRESCOT et al., 2005; ROQUE; PEREIRA, 2012) e da experiência profissional de um dos autores, professor de Física da Educação Básica, elaborou-se uma proposta didática com o objetivo de fazer com que os estudantes superassem suas dificuldades de aprendizagem no estudo de gráficos.

A experiência didática descrita e analisada neste artigo foi desenvolvida à luz das orientações curriculares contidas em documentos oficiais de ensino Brasil (2000) e alicerçada na teoria sobre aprendizagem e desenvolvimento de David Ausubel (MOREIRA, 2011).

Por entender que a superação de dificuldades de aprendizagem dos alunos deva ser objetivo do trabalho de professores das diversas áreas do currículo escolar, foi desenvolvida uma proposta de Unidade Didática composta por diferentes estratégias de ensino voltadas à aprendizagem significativa de conhecimentos básicos de Matemática, fundamentais para o entendimento de conceitos de Física. Num segundo momento, esses conhecimentos foram aplicados na construção e interpretação de gráficos da Cinemática.

A experiência didática em questão foi desenvolvida com duas turmas de $1^{\circ}$ ano do Ensino Médio, de uma escola estadual do município de Candiota, RS. Trata-se da aplicação de uma Unidade Didática dividida em dois módulos, nos quais são empregados recursos lúdicos e de robótica, em especial a plataforma Arduino ${ }^{2}$. Assim, o primeiro módulo prevê atividades como o jogo batalha naval, indicadas para o estudo do plano cartesiano, conhecimento necessário para o entendimento e o estudo de gráficos da Cinemática. O segundo módulo,

\footnotetext{
2 Arduino é uma plataforma eletrônica de código aberto baseado em hardware e software de fácil utilização, sendo apropriada para o desenvolvimento de projetos interativos. Fonte: <https://www.arduino.cc/>.
} 
com ênfase no ensino de Física, propõe atividades voltadas para a elaboração e interpretação de gráficos em Cinemática, utilizando tecnologias computacionais, contempladas na construção de carrinhos automatizados e o uso de um sensor de movimento associado a uma placa microcontrolada Arduino. A Unidade Didática foi desenvolvida em aulas de Seminário Integrado, componente curricular introduzido no currículo do Ensino Médio, pela Secretaria Estadual de Educação do Rio Grande do Sul (SEDUC-RS), na modalidade de Ensino Médio Politécnico (RIO GRANDE DO SUL, 2011).

\section{Atividades lúdicas e computacionais no ensino de gráficos}

Conscientes da importância do estudo dos gráficos e da dificuldade observada nos estudantes em geral, quando necessitam construí-los ou interpretá-los, os autores buscaram estudos e pesquisas que identificam problemas na aprendizagem de gráficos e apontam alternativas que conduzam a uma aprendizagem significativa deste conteúdo (ROQUE; PEREIRA, 2012; PRESCOTT et al., 2005; ARAUJO; VEIT; MOREIRA, 2004; WRASSE et al., 2013).

Roque e Pereira (2012) desenvolveram uma atividade com uma turma de $8^{\circ}$ ano do Ensino Fundamental partindo de situações vivenciais dos alunos, utilizando recursos como mapa do município, localização e orientação de quadras e ruas, para a criação de situações de ensino que levassem ao entendimento do conceito de plano cartesiano. A proposta teve por objetivo trabalhar os conceitos de ponto de origem e deslocamento no plano, através de uma abordagem diferente do ensino realizado usualmente, a partir do estudo da definição, da proposição de exemplos e de exercícios.

Também sobre ensino do plano cartesiano, Prescott et al. (2005) apresentam uma proposta de trabalho que utiliza o jogo batalha naval para introduzir gráficos e levar os alunos à identificação de coordenadas cartesianas. Resultados desse trabalho apontam dificuldades dos alunos na localização das embarcações no jogo batalha naval e na construção de figuras geométricas no plano. Os autores desse trabalho destacam que a localização do zero, como origem de um sistema de coordenadas, também é de difícil compreensão para os estudantes.

Com aplicação voltada para o ensino de Física e ênfase no estudo da Cinemática, Araujo, Veit e Moreira (2004) utilizaram atividades de modelagem computacional na construção e interpretação de gráficos de movimento. Os autores citam estudos bem sucedidos que descrevem ganhos significativos na interpretação de gráficos utilizando o computador para a aquisição de dados em tempo real (proposta MBL: "Microcomputer-Based-Laboratory"). As atividades permitiam aos alunos observar o traçado em tempo real dos gráficos, registrando uma contínua e forte predisposição deles em realizar as atividades no computador. Tanto na proposta MBL, como nas atividades de modelagem, foi constatada uma influência positiva na predisposição dos estudantes em aprender Física.

Ainda direcionado ao estudo da Física, com aplicação na Cinemática, Wrasse et al. (2013) desenvolveram um trabalho utilizando tecnologias de informação e comunicação 
(TICs) como elemento facilitador para aprendizagem de gráficos de movimento na Cinemática. Os autores usaram a plataforma microcontrolada Arduino para construir um "carrinho automatizado", o qual realiza movimentos com velocidades e sentidos pré-programados, sendo estes apropriados à interpretação e análise de gráficos. Os resultados da pesquisa demonstram o caráter motivador que a experiência proporcionou aos alunos ao desenvolverem as atividades.

\section{Aplicação da unidade didática}

Os trabalhos de Roque e Pereira (2012) e de Prescott et al. (2005) constituíram fonte de inspiração para a elaboração do primeiro módulo didático deste trabalho. Roque e Pereira (2012) utilizaram situações vivenciais para despertar o interesse dos alunos pelo assunto, mas, para concentrar a atenção dos estudantes em torno dos objetivos propostos, este primeiro módulo da Unidade Didática inclui atividades interativas propostas no trabalho de Prescott et al. (2005). Na sequência, introduz-se o ensino de plano cartesiano envolvendo situações reais. O segundo módulo da proposta didática teve como base os trabalhos de Araujo, Veit e Moreira (2004) e de Wrasse et al. (2013), que analisaram a utilização de um carrinho automatizado para o ensino de conceitos de Física.

No presente trabalho, o diferencial na utilização do carrinho automatizado concentrase, principalmente, na programação da plataforma, na qual foi introduzido o controle à distância do carrinho (via controle remoto), o que permitiu um forte envolvimento dos estudantes com o experimento e a oportunidade de realizar desafios com maior grau de abstração. Os resultados da pesquisa demonstram o caráter motivador que a experiência proporcionou aos alunos ao desenvolverem as atividades.

As atividades propostas na Unidade Didática foram desenvolvidas em pequenos grupos, incentivando a interação entre os alunos e entre alunos e o professor. Inicialmente, foi feito um levantamento prévio dos conhecimentos dos estudantes sobre o objeto de estudo, explorando esses conhecimentos durante as aulas e os adequando aos objetivos da intervenção, de forma a despertar a predisposição dos alunos em aprender, com materiais instrucionais que fossem significativos para eles.

Devido à disponibilidade oferecida pela escola, a Unidade Didática foi desenvolvida em aulas de Seminário Integrado do Ensino Médio Politécnico, componente curricular da parte diversificada do currículo. O Primeiro Módulo Didático abordou o estudo do plano cartesiano e foi desenvolvido ao longo de duas semanas, totalizando 09 horas/aula de trabalho. A aplicação do Segundo Módulo Didático, destinado à construção e interpretação de gráficos de movimento, em Cinemática, foi realizada nas três semanas seguintes, totalizando 11 horas/aula. Finalizando a Unidade Didática, procedeu-se ao acompanhamento dos projetos desenvolvidos pelos alunos em diferentes áreas de conhecimento, examinando a forma de aplicação e o uso de gráficos. 
O Quadro 1 apresenta as atividades propostas para cada módulo da Unidade Didática.

Quadro 1 - Relação de atividades dos dois módulos didáticos.

\begin{tabular}{|c|c|}
\hline \multicolumn{2}{|r|}{ Primeiro módulo didático (estudo do plano cartesiano) } \\
\hline Atividade 1.1 & Aplicação do jogo batalha naval. \\
\hline Atividade 1.2 & $\begin{array}{l}\text { Desafio } \mathrm{n}^{\mathrm{o}} 1 \text { - Explorando a batalha naval para aprendizagem sobre a localização } \\
\text { de pontos em um sistema de coordenadas. }\end{array}$ \\
\hline Atividade 1.3 & Desafio $^{\circ} 2$ - Consolidação do conhecimento sobre plano cartesiano. \\
\hline Atividade 1.4 & Atividade complementar: Consolidação do conhecimento sobre plano cartesiano. \\
\hline \multicolumn{2}{|r|}{ Segundo módulo didático (estudo de gráficos em Cinemática) } \\
\hline Atividade 2.1 & $\begin{array}{l}\text { Atividade } \mathrm{N}^{\mathrm{o}} 1 \text { - Utilizando o carrinho automatizado - Uso da plataforma } \\
\text { ARDUÍNO para o ensino-aprendizagem de gráficos da Cinemática. }\end{array}$ \\
\hline Atividade 2.2 & $\begin{array}{l}\text { Atividade } \mathrm{N}^{\circ} 2 \text { - Utilizando o carrinho automatizado - Consolidação dos } \\
\text { conceitos de deslocamento e velocidade por meio de gráficos. }\end{array}$ \\
\hline Atividade 2.3 & $\begin{array}{l}\text { Atividade } \mathrm{N}^{\mathrm{o}} 3 \text { - Consolidação dos conceitos de deslocamento e velocidade por } \\
\text { meio de gráficos. }\end{array}$ \\
\hline Atividade 2.4 & $\begin{array}{l}\text { Atividade } \mathrm{N}^{\circ} \text { 4: Utilização da plataforma ARDUÍNO com o sensor de posição para } \\
\text { interpretar e construir gráficos do movimento. }\end{array}$ \\
\hline
\end{tabular}

Fonte: Os autores.

Participaram da aplicação da Unidade Didática e da pesquisa 39 estudantes de duas turmas de $1^{\circ}$ ano do Ensino Médio do turno da manhã. Uma turma era composta por 22 estudantes (Turma A) e a outra 17 (Turma B). Nas duas turmas, a faixa etária dos estudantes era de 14 a 16 anos e todos tinham dedicação exclusiva aos estudos.

\section{III.1 Objetivos e desenvolvimento dos módulos didáticos}

As atividades desenvolvidas no primeiro módulo da unidade didática e os objetivos de aprendizagem são descritos no quadro 2.

Quadro 2- Atividades e objetivos do primeiro módulo didático.

\begin{tabular}{|l|c|c|}
\hline \multicolumn{3}{|c|}{ Atividades e objetivos do primeiro módulo didático } \\
\hline Descrição da Atividade & $\begin{array}{c}\text { Objetivos de aprendizagem } \\
\text { Os alunos deverão: }\end{array}$ & $\begin{array}{c}\text { Aul } \\
\text { as }\end{array}$ \\
\hline \multicolumn{2}{|c|}{ Atividade 1 - Realização do pré-teste e jogo batalha naval } \\
\hline $\begin{array}{l}\text { Apresentação da atividade à } \\
\text { turma, aplicação do pré-teste } \\
\text { e realização do jogo. }\end{array}$ & $\begin{array}{l}1.1 \text { Demonstrar habilidade espacial na localização de } \\
\text { objetos em um plano, bem como a capacidade de } \\
\text { abstração, relacionando o jogo com o plano cartesiano. }\end{array}$ & 1 e 2 \\
\hline
\end{tabular}




\begin{tabular}{|c|c|c|}
\hline $\begin{array}{l}\text { Retomada do jogo e } \\
\text { realização de um desafio. }\end{array}$ & & 3 e 4 \\
\hline \multicolumn{3}{|c|}{ Atividade 2 - Consolidando o plano cartesiano } \\
\hline $\begin{array}{l}\text { Discussão dos conteúdos } \\
\text { formais do plano cartesiano, } \\
\text { revisão conceitual e } \\
\text { histórica; } \\
\text { Apresentação de um desafio } \\
\text { para resolução. }\end{array}$ & $\begin{array}{l}\text { 1.2 Compreender os conceitos de reta numérica, eixos } \\
\text { ortogonais e plano cartesiano, além de reconhecer as } \\
\text { coordenadas de pontos distintos no plano cartesiano. } \\
\text { 1.3 Interpretar e demonstrar habilidade na localização } \\
\text { de pontos frente a um problema proposto. }\end{array}$ & 5 e 6 \\
\hline $\begin{array}{l}\text { Aplicação prática no pátio } \\
\text { da escola: a partir de um } \\
\text { plano cartesiano desenhado } \\
\text { na quadra de esportes; } \\
\text { Simulação de uma jogada de } \\
\text { futebol, estratégia para } \\
\text { cálculo de distâncias entre } \\
\text { pontos no plano cartesiano. }\end{array}$ & $\begin{array}{l}\text { Trabalhar colaborativamente, no intuito de: } \\
\text { 1.4 Identificar pontos e reconhecer coordenadas no } \\
\text { plano cartesiano. } \\
1.5 \text { Calcular distâncias entre pontos no plano } \\
\text { cartesiano. }\end{array}$ & $\begin{array}{l}7,8 \\
\text { e } 9\end{array}$ \\
\hline
\end{tabular}

Fonte: Os autores.

Para a consecução dos objetivos da Unidade Didática, as aulas foram planejadas de modo a se promover um nível crescente de dificuldades, propiciando uma diferenciação progressiva ${ }^{3}$ seguida de uma reconciliação integrativa, conforme acepção de aprendizagem de Ausubel (MOREIRA, 2011). Considerando este pressuposto, foi usado, no primeiro módulo, o recurso didático proporcionado pelo jogo batalha naval, adaptado do trabalho de Prescott et al. (2005). Esse recurso didático tem por objetivo estimular a predisposição dos estudantes para uma aprendizagem significativa por meio de situações que promovam a localização de pontos em um plano cartesiano.

Inicialmente, foi aplicado um pré-teste para obter dados sobre os conhecimentos prévios dos alunos referentes à análise e interpretação de gráficos. Conseguiu-se identificar algumas dificuldades dos alunos na interpretação de dados constantes em gráficos, principalmente em relação à transposição de dados tabelados para os respectivos gráficos. A partir desses dados, a estratégia didática foi conduzida conforme a teoria de aprendizagem significativa de Ausubel (MOREIRA, 2011).

Na sequência deste primeiro módulo, os alunos jogaram uma batalha naval para, a partir de uma competição entre duas equipes compostas por duplas, desenvolverem um trabalho baseado na interação. A formação de duplas teve por objetivo fazer com que os

\footnotetext{
${ }^{3}$ Concepção ausbeliana em que a assimilação de conceitos é favorecida quando os componentes mais gerais e inclusivos de um conceito são apresentados em primeiro lugar, devendo ser progressivamente diferenciados em seus detalhes e especificidades (MOREIRA, 2011).
} 
alunos interagissem de modo que se um deles não estivesse entendendo o desafio proposto na atividade pudesse ser ajudado pelo colega. Ao serem trabalhados os conceitos de reta numérica, sistema de eixos cartesianos e localização de pontos no plano cartesiano, buscou-se fazer com que os alunos ancorassem conhecimentos de representação de objetos em um plano cartesiano aos conhecimentos prévios (subsunçores) de orientação espacial. A Fig. 1 mostra o recorte de um desafio proposto na atividade com o jogo batalha naval.

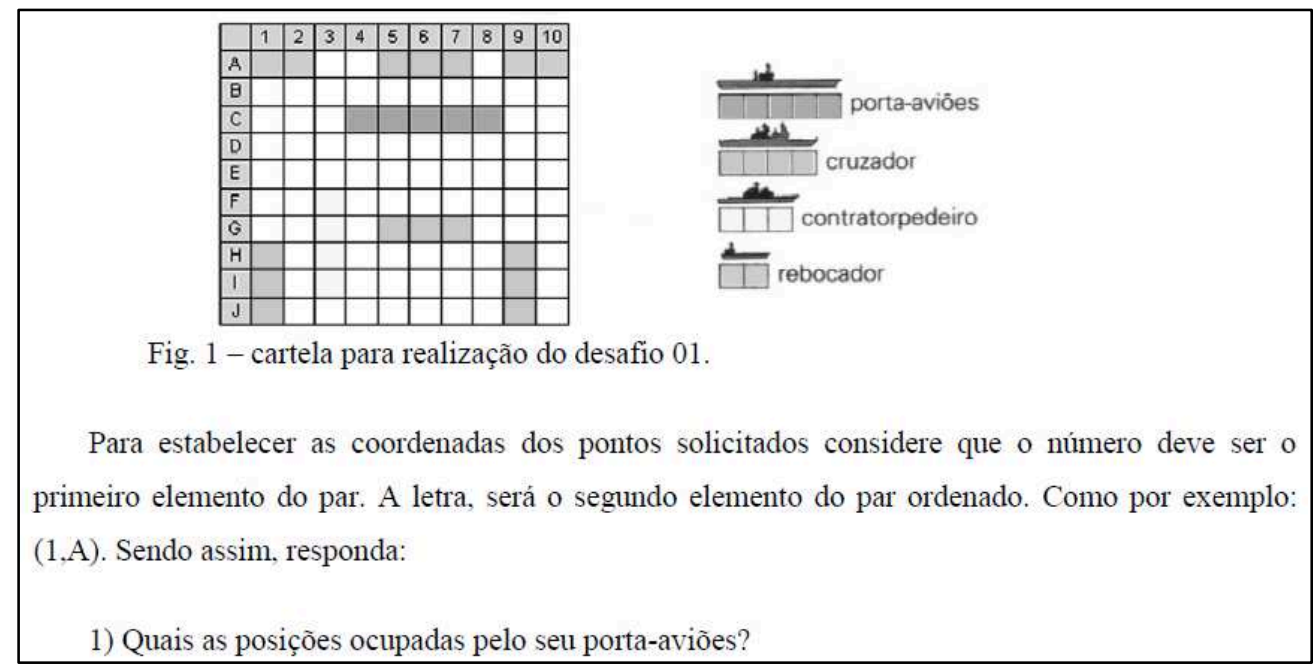

Fig. 1 - Recorte do desafio proposto na atividade. Fonte: Adaptado de Prescott et al. (2005).

$\mathrm{Na}$ abordagem conceitual desenvolvida após o jogo batalha naval, procurou-se observar os princípios da Diferenciação Progressiva e da Reconciliação Integrativa, propostos por Ausubel (MOREIRA, 2011). Nesse sentido, no início da atividade foram apresentados conceitos mais gerais e inclusivos como plano cartesiano e pares ordenados, os quais, aos poucos, foram sendo diferenciados como eixo das ordenadas e das abscissas, escalas e distâncias entre pontos. Já a reconciliação integrativa foi explorada na medida em que inicialmente se debateu as principais ideias trabalhadas na atividade anterior, buscando apontar similaridades e diferenças importantes. Nesta atividade, foram trabalhados os conceitos de reta numérica e localização de pontos no plano cartesiano. A atividade consistiu em localizar e/ou identificar as cidades ou pontos sugeridos em um recorte do mapa da região sudoeste do Estado do Rio Grande do Sul (RS) (Fig. 2), os quais foram explorados em nove questões.

Concluindo esse primeiro módulo, os alunos receberam um terceiro conjunto de tarefas (em forma de guia) contendo um plano cartesiano com quatro pontos delimitados e uma situação problema (representar em um plano cartesiano desenhado no pátio da escola os pontos coordenados representados em papel milimetrado (Fig. 3)). É importante ressaltar que os alunos receberam um guia de orientação em cada atividade desenvolvida. $\mathrm{O}$ guia norteava 
a dinâmica da execução das tarefas através de questões e desafios, de modo a permitir avaliar o desempenho dos estudantes.

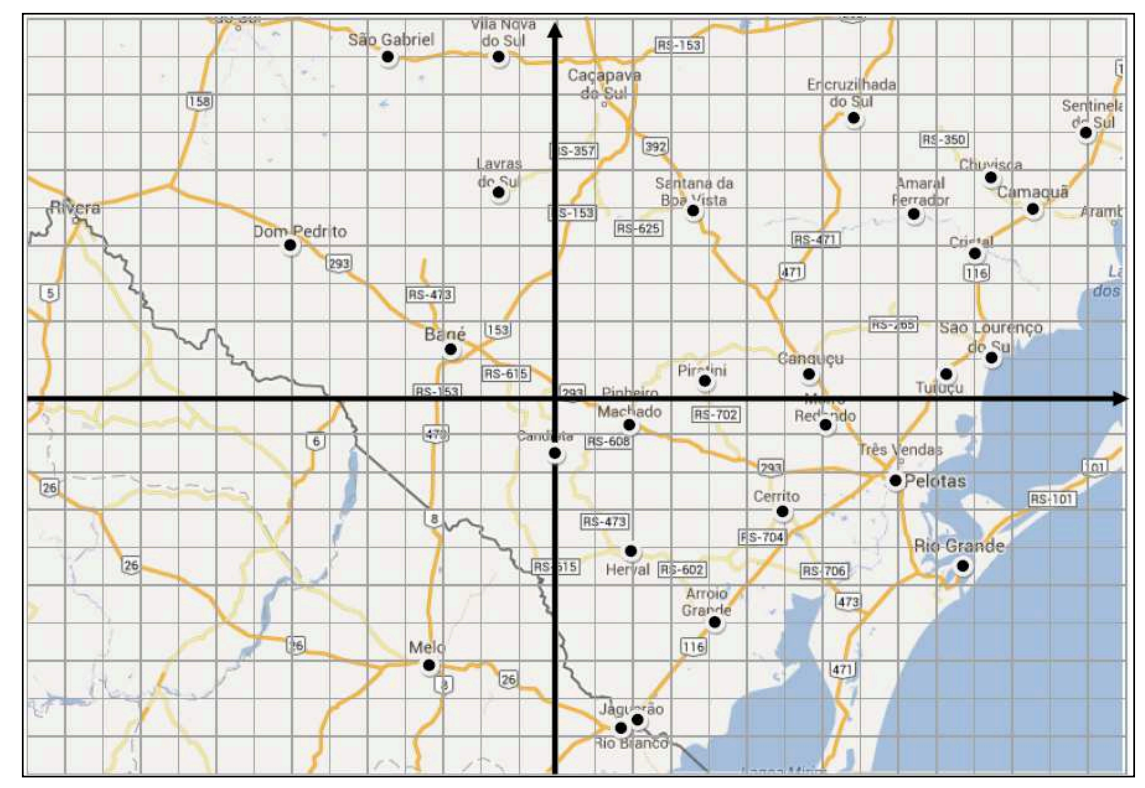

Fig. 2 - Recorte do mapa da região Sudoeste do RS, utilizado para localização de pontos e coordenadas. Fonte: Adaptado pelos autores a partir de: $<$ https://www.google.com.br/maps $>$.

Na primeira parte do guia de tarefas, os alunos deveriam estabelecer corretamente as coordenadas dos pontos no plano e discutir a melhor forma de calcular as distâncias entre os pontos.

A Fig. 3 mostra o plano cartesiano apresentado aos alunos com os pontos demarcados e o exemplo de uma questão solicitada nesta atividade.

Após determinar as coordenadas e calcular as distâncias, esse conjunto de tarefas previa a comprovação das medidas através da construção de um plano cartesiano desenhado na quadra de esportes da escola. Para desenhar esse plano, os grupos usaram cordas e trenas para fazer a medição das distâncias, localizar os pontos e comparar os resultados obtidos em sala de aula. Os valores medidos na prática foram bem próximos daqueles calculados em sala. A Fig. 4 mostra, em (a), o cálculo realizado em sala e, em (b), um grupo de alunos utilizando as cordas e realizando as medições no plano cartesiano desenhado na quadra de esportes. 


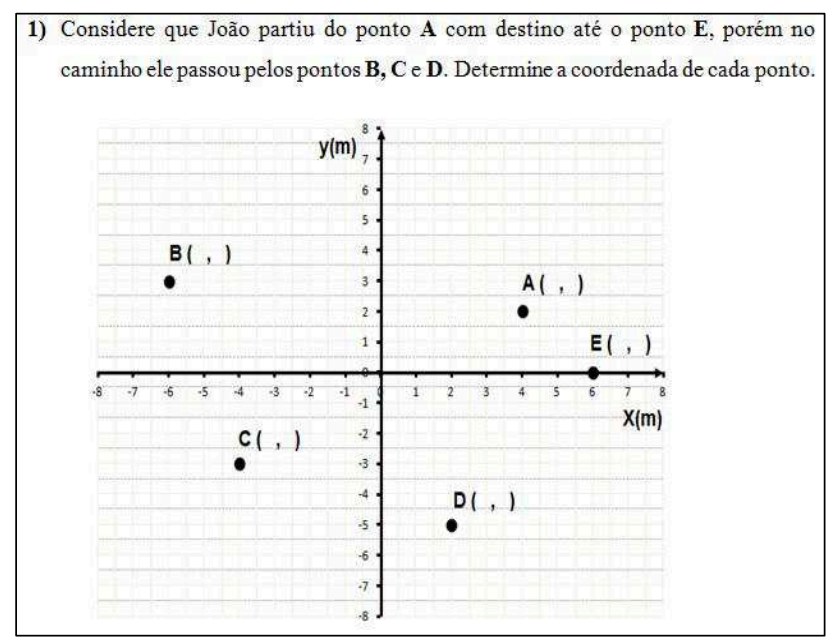

Fig. 3 - Plano cartesiano apresentado para localização de pontos e cálculo de distâncias. Fonte: Os autores.

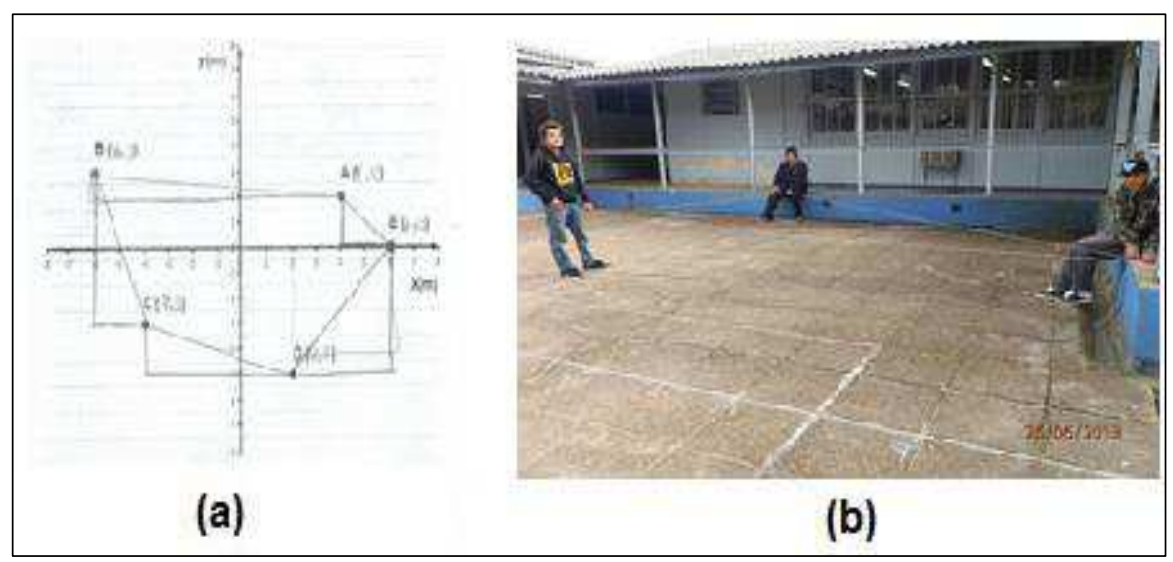

Fig. 4 - (a) cálculo realizado em sala; (b) Alunos fazendo medições de distâncias no plano cartesiano desenhado no pátio da escola. Fonte: Os autores.

A aplicação da Unidade Didática teve continuidade com o desenvolvimento do segundo módulo, que previu o uso de tecnologias computacionais como recurso facilitador do ensino e da aprendizagem de gráficos da Cinemática. Nesse segundo módulo, foi utilizado um carrinho automatizado a partir da plataforma microcontrolada Arduíno, conforme detalhado no trabalho de Wrasse et al. (2013). Os recursos utilizados neste módulo e os objetivos de aprendizagem são apresentados no Quadro 3. 
Quadro 3 - Recursos utilizados e objetivos do segundo módulo didático.

\begin{tabular}{|c|c|c|}
\hline \multicolumn{3}{|c|}{ Atividades e objetivos do segundo módulo didático } \\
\hline Descrição da Atividade & Objetivos de aprendizagem & $\begin{array}{c}\text { Aul } \\
\text { as }\end{array}$ \\
\hline \multicolumn{3}{|c|}{ Atividade 3 - Utilizando o carrinho automatizado } \\
\hline $\begin{array}{l}\text { Apresentação do carrinho, } \\
\text { tecendo considerações sobre o } \\
\text { Arduíno e novas tecnologias, } \\
\text { abrindo espaço para discussão } \\
\text { sobre a proposta de trabalho. }\end{array}$ & \multirow{2}{*}{$\begin{array}{l}\text { Os estudantes deverão: } \\
\text { 2.1 Expressar expectativas e sugestões para a } \\
\text { realização das atividades. } \\
\text { 2.2 Relacionar os diferentes movimentos } \\
\text { realizados pelo carrinho com os respectivos } \\
\text { gráficos da cinemática, identificando o gráfico } \\
\text { que represente o movimento realizado. } \\
\text { 2.3 Coletar corretamente dados de tempo e } \\
\text { posição. }\end{array}$} & 10 \\
\hline $\begin{array}{l}\text { Utilização do carrinho em } \\
\text { diferentes velocidades, colocando } \\
\text { o desafio da identificação dos } \\
\text { movimentos através de gráficos. }\end{array}$ & & 11 \\
\hline $\begin{array}{l}\text { Através da observação do } \\
\text { movimento do carrinho e da } \\
\text { coleta de dados, promover a } \\
\text { construção dos respectivos } \\
\text { gráficos pelos grupos. }\end{array}$ & $\begin{array}{l}\text { A partir dos dados coletados: } \\
2.4 \text { Construir e interpretar o gráfico da posição } \\
\text { vs. Tempo. } \\
2.5 \text { Construir e interpretar o gráfico da velocidade } \\
\text { vs. Tempo. }\end{array}$ & 12 \\
\hline $\begin{array}{l}\text { Retomada da construção dos } \\
\text { gráficos, procurando esclarecer }\end{array}$ & \multirow{2}{*}{$\begin{array}{l}\text { A partir dos gráficos recebidos: } \\
\text { 2.6 Reproduzir a velocidade com o carrinho. } \\
\text { 2.7 Reconhecer e produzir a variação na } \\
\text { velocidade. }\end{array}$} & 14 \\
\hline $\begin{array}{l}\text { Apresentação de gráficos de } \\
\text { Cinemática relativos a diferentes } \\
\text { movimentos. }\end{array}$ & & 15 \\
\hline Realização do pós-teste & $\begin{array}{l}\text { 2.8 Demonstrar habilidade de análise e } \\
\text { interpretação de gráficos, através da resolução } \\
\text { dos problemas propostos. }\end{array}$ & 16 \\
\hline \multirow{3}{*}{$\begin{array}{l}\text { Apresentação dos carrinhos pré- } \\
\text { programados com diferentes } \\
\text { velocidades e sentido de } \\
\text { deslocamento. }\end{array}$} & \multirow{3}{*}{$\begin{array}{l}2.9 \text { Reconhecer os diferentes tipos de movimento, } \\
\text { associando aos respectivos gráficos da posição vs. } \\
\text { tempo; construir o gráfico da velocidade } v s \text {. } \\
\text { tempo correspondente. } \\
\text { 2.10 Proceder à descrição verbal e/ou textual do } \\
\text { movimento. }\end{array}$} & 17 \\
\hline & & \\
\hline & & 18 \\
\hline \multirow{2}{*}{$\begin{array}{l}\text { Utilização da plataforma Arduíno } \\
\text { com sensor ultrassônico para } \\
\text { construção de gráficos do } \\
\text { movimento em tempo real }\end{array}$} & \multirow{2}{*}{$\begin{array}{l}\text { 2.11 Interpretar e expressar dados constantes em } \\
\text { gráficos do movimento uniforme; construir estes } \\
\text { gráficos, a partir de determinado movimento. }\end{array}$} & 19 \\
\hline & & 20 \\
\hline
\end{tabular}

Fonte: Os autores.

As atividades do segundo módulo didático buscaram estimular a predisposição dos estudantes em aprender a reunir dados de tempo e posição de cinco carrinhos automatizados, 
para posterior cálculo da sua velocidade, assim como utilizar os dados tabelados para construir e interpretar gráficos da posição versus tempo e da velocidade versus tempo.

Para encerramento do módulo, uma última atividade foi desenvolvida, utilizando a plataforma microcontrolada Arduino com um sensor de movimento para a construção de gráficos de movimento em tempo real. Tal atividade fez parte dos instrumentos avaliativos da Unidade Didática no sentido de buscar indícios da ocorrência da aprendizagem significativa sobre a construção e interpretação de gráficos. Conforme sugere Moreira (2011), uma maneira de buscar evidências da aprendizagem é formular questões e problemas de maneira nova e não familiar, exigindo do aluno algum tipo de transformação do conhecimento adquirido. Assim, esta atividade avaliativa apresenta uma situação para análise do movimento pelos estudantes, em um contexto diferente daquele na qual foi utilizado o material instrucional.

Para essa atividade foi desenvolvido um aparato experimental, contendo um sensor sonar capaz de captar a posição de um determinado objeto. Através do software PLX-DAQ ${ }^{4}$, os alunos puderam construir gráficos da posição vs. tempo correspondente a esse movimento em tempo real.

Para a realização das tarefas previstas na atividade, foi disponibilizado um guia com orientações. Os grupos receberam um conjunto de quatro gráficos da posição versus tempo, representando movimentos de um móvel em trajetória retilínea com módulos e sentidos de velocidade que variavam de um gráfico para outro.

Cada grupo teve 10 minutos para reproduzir o movimento representado nos gráficos, utilizando o instrumento preparado através da plataforma Arduino ${ }^{5}$. Tal instrumento registrou a forma como os grupos interpretaram e reproduziram o movimento constante nos gráficos recebidos para análise.

\section{Resultados e discussão}

Os dados reunidos na aplicação da unidade didática foram analisados quantitativamente, relacionando os resultados do desempenho dos estudantes em um pré-teste e num pós-teste. Essa análise foi complementada por um estudo qualitativo sobre o desempenho dos estudantes, em relação aos objetivos de aprendizagem apresentados nos quadros 2 e 3 , realizado a partir dos relatos das atividades desenvolvidas em cada aula.

Com a aplicação dos testes, buscou-se analisar a fidedignidade do instrumento no que se refere à estabilidade, à reprodutibilidade, à precisão das medidas com ele obtidas, isto é, ao grau de consistência dos valores medidos. Conforme Dorneles, Veit e Moreira (2005), "Uma maneira de se estimar o coeficiente de fidedignidade é decompondo a variância do

\footnotetext{
${ }^{4}$ Este software foi desenvolvido pela empresa ParallaxInc com o propósito de possibilitar a análise em tempo real de dados experimentais a partir de uma planilha eletrônica. Mais informações em: <http://www.parallax.com/downloads/plx-daq>. Acesso em: 05 dez. 2014.

${ }^{5}$ Esse aparato experimental é descrito em detalhes no trabalho de Dworakowski (2015).
} 
escore total em uma parcela atribuída ao que há de comum entre os escores parciais e outra parte ao erro da medida". O coeficiente alfa de Cronbach (CRONBACH, 1951, apud MOREIRA; SILVEIRA, 1993) foi utilizado para estimar a parcela fidedigna comum aos itens dos testes. O valor mínimo aceitável para um coeficiente de fidedignidade, que compare grupos em médias, como no presente caso, é 0,7 (op. cit., p. 83). O pós-teste alcançou um coeficiente alfa de Cronbach satisfatório de 0,72. Já o pré-teste alcançou índice baixo: 0,63. Os autores atribuem esse índice baixo no pré-teste aos escores baixos dos alunos, os quais apresentaram baixa variabilidade. No quadro 4, são transcritos os escores obtidos pelos alunos no pré e pós-teste e a respectiva análise destes testes.

Quadro 4 - Evolução no desempenho das turmas entre o pré e o pós-teste.

\begin{tabular}{|c|c|c|c|c|c|c|c|c|c|c|c|}
\hline \multicolumn{6}{|c|}{ Turma "A" (22 alunos) } & \multicolumn{6}{|c|}{ Turma "B" (17 alunos) } \\
\hline \multicolumn{3}{|c|}{ Pré-teste } & \multicolumn{3}{|c|}{ Pós-teste } & \multicolumn{3}{|c|}{ Pré-teste } & \multicolumn{3}{|c|}{ Pós-teste } \\
\hline Média & $\begin{array}{l}\text { Desvio } \\
\text { Padrão }\end{array}$ & $\begin{array}{c}\text { Desvio } \\
\text { Padrão } \\
\text { da } \\
\text { média }\end{array}$ & Média & $\begin{array}{l}\text { Desvio } \\
\text { Padrão }\end{array}$ & $\begin{array}{c}\text { Desvio } \\
\text { Padrão } \\
\text { da } \\
\text { média }\end{array}$ & Média & $\begin{array}{l}\text { Desvio } \\
\text { Padrão }\end{array}$ & $\begin{array}{c}\text { Desvio } \\
\text { Padrão } \\
\text { da } \\
\text { média }\end{array}$ & Média & $\begin{array}{l}\text { Desvio } \\
\text { Padrão }\end{array}$ & $\begin{array}{c}\text { Desvio } \\
\text { Padrão } \\
\text { da } \\
\text { média }\end{array}$ \\
\hline 5,00 & 2,18 & 0,47 & 6,27 & 1,96 & 0,42 & 4,71 & 2,20 & 0,53 & 5,24 & 1,92 & 0,47 \\
\hline \multicolumn{9}{|c|}{ Média geral do Pré-teste (Turma “A" + Turma "B") } & \multicolumn{3}{|c|}{4,87} \\
\hline \multicolumn{9}{|c|}{ Desvio Padrão geral do Pré-teste } & \multicolumn{3}{|c|}{2,17} \\
\hline \multicolumn{9}{|c|}{ Desvio Padrão geral do Pré-teste da média } & \multicolumn{3}{|c|}{0,35} \\
\hline \multicolumn{9}{|c|}{ Média geral do Pós-teste (Turma "A" + Turma "B") } & \multicolumn{3}{|c|}{5,87} \\
\hline \multicolumn{9}{|c|}{ Desvio Padrão geral do Pós-teste } & \multicolumn{3}{|c|}{2,17} \\
\hline \multicolumn{9}{|c|}{ Desvio Padrão geral do Pós-teste da média } & \multicolumn{3}{|c|}{0,32} \\
\hline \multicolumn{9}{|c|}{$\begin{array}{l}\text { Nível de significância estatística entre as médias dos pré e pós-testes considerando } \\
\text { as duas turmas ( } 39 \text { alunos) }\end{array}$} & \multicolumn{3}{|c|}{ Menor que $0,01(t=2,98)$} \\
\hline
\end{tabular}

Fonte: Os autores.

Embora o nível de significância estatística tenha sido inferior a 0,01 (probabilidade inferior a $1 \%$ de que a diferença entre as médias do pré e pós-teste tenha ocorrido por acaso) esperava-se uma média superior nos pós-teste, pois os alunos participaram ativamente das atividades e demonstraram entendimento dos processos de reunir dados e de construir e interpretar gráficos. Apesar de se possuir poucas evidências dos fatores que contribuíram para a média de acertos no pós-teste não ultrapassar $60 \%$, atribui-se esse resultado a fatores ligados à falta de atenção e de motivação para realizar uma avaliação individual com pouca influência na nota final do trimestre. A análise quantitativa foi complementada com uma análise qualitativa realizada a partir das respostas dos guias preenchidos pelos grupos. 
Para análise qualitativa das respostas dos estudantes, foi estabelecido um sistema de categorias. Para aqueles guias em que as questões permitiam uma análise tanto quantitativa como qualitativa, as respostas dos grupos foram categorizadas em respostas esperadas (RE), respostas parciais (RP), respostas inadequadas (RI) e respostas em branco (RB).

No trabalho de Dworakowski (2015) são apresentados em detalhes os procedimentos adotados na análise qualitativa, incluindo exemplos de respostas dos alunos. No Quadro 5, é apresentada apenas uma síntese da distribuição de respostas por guia analisado.

Quadro 5 - Distribuição geral das respostas dos alunos apresentadas nos guias selecionados para análise.

\begin{tabular}{|c|c|c|c|c|c|c|c|c|c|}
\hline \multicolumn{2}{|c|}{$\begin{array}{c}\text { Guia } \\
\text { trabalhado }\end{array}$} & \multicolumn{2}{|c|}{ Guia D } & \multicolumn{2}{|c|}{ Guia E } & \multicolumn{2}{|c|}{ Guia F } & \multicolumn{2}{|c|}{ Guia G } \\
\hline \multicolumn{2}{|c|}{ Atividade (aulas) } & \multicolumn{2}{|c|}{$\begin{array}{l}\text { Atividade } 1 \\
(3 \text { e } 4)\end{array}$} & \multicolumn{2}{|c|}{$\begin{array}{l}\text { Atividade } 2 \\
(5 \text { e } 6)\end{array}$} & \multicolumn{2}{|c|}{$\begin{array}{l}\text { Atividade } 2 \\
\text { (compl.), }(7,8 \mathrm{e} \\
9)\end{array}$} & \multicolumn{2}{|c|}{$\begin{array}{l}\text { Atividade } 3 \\
(10,11,12 \mathrm{e} \\
13)\end{array}$} \\
\hline \multicolumn{2}{|c|}{$\begin{array}{l}\text { Objetivos de } \\
\text { aprendizagem }\end{array}$} & \multicolumn{2}{|l|}{1.1} & \multicolumn{2}{|c|}{$\begin{array}{c}1.2,1.3,1.4 \mathrm{e} \\
1.5\end{array}$} & \multicolumn{2}{|c|}{$1.3,1.4$ e 1.5} & \multicolumn{2}{|c|}{2.1 e 2.2} \\
\hline \multicolumn{2}{|c|}{$\begin{array}{l}\mathrm{N}^{0} \text { de questões } \\
\text { ou itens } \\
\text { analisados }\end{array}$} & \multicolumn{2}{|c|}{06} & \multicolumn{2}{|c|}{13} & \multicolumn{2}{|c|}{10} & \multicolumn{2}{|c|}{02} \\
\hline \multicolumn{2}{|c|}{$\begin{array}{l}N^{0} \text { de grupos } \\
\text { formados }\end{array}$} & \multicolumn{2}{|c|}{21} & \multicolumn{2}{|c|}{13} & \multicolumn{2}{|c|}{08} & \multicolumn{2}{|c|}{07} \\
\hline \multicolumn{2}{|c|}{$\begin{array}{l}\mathrm{N}^{0} \text { de respostas } \\
\text { avaliadas }\end{array}$} & \multicolumn{2}{|c|}{126} & \multicolumn{2}{|c|}{169} & \multicolumn{2}{|c|}{80} & \multicolumn{2}{|c|}{14} \\
\hline \multicolumn{2}{|c|}{$\begin{array}{c}\text { Respostas e } \\
\text { percentual }\end{array}$} & Ocor. & $\%$ & Ocor. & $\%$ & Ocor. & $\%$ & Ocor. & $\%$ \\
\hline \multirow{4}{*}{ 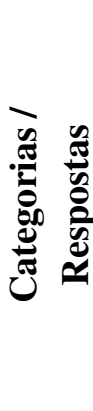 } & $\begin{array}{l}\text { Respostas } \\
\text { Esperadas }\end{array}$ & 104 & 82,5 & 118 & 69,8 & 75 & 93,8 & 06 & 42,8 \\
\hline & $\begin{array}{l}\text { Respostas } \\
\text { Parciais }\end{array}$ & 11 & 8,7 & 32 & 18,9 & 01 & 1,2 & 04 & 28,6 \\
\hline & $\begin{array}{l}\text { Respostas } \\
\text { Inadequadas }\end{array}$ & 10 & 8,0 & 07 & 4,2 & 04 & 5,0 & 04 & 28,6 \\
\hline & $\begin{array}{l}\text { Respostas } \\
\text { em Branco }\end{array}$ & 01 & 0,8 & 12 & 7,1 & 00 & 0,0 & 00 & 0,0 \\
\hline
\end{tabular}

Fonte: Os autores.

O Guia G, que contempla a análise e interpretação de gráficos do movimento feita pelos alunos, aponta um declínio de respostas esperadas, chegando a um índice inferior a $50 \%$. Tal resultado obtido na atividade introdutória ao trabalho com gráficos do movimento vem reforçar possíveis concepções em desacordo com a concepção da Física sobre a representação de movimentos em gráficos. Identificamos, na análise qualitativa dos dados, 
algumas dificuldades que os alunos têm ao chegar ao Ensino Médio, tais como: i) inobservância da identificação das grandezas que constituem os eixos cartesianos; ii) confusão sobre a grandeza Cinemática representada pela posição da reta no gráfico; iii) ligação da figura do gráfico com a trajetória do movimento realizado. As dificuldades identificadas corroboram o trabalho de Araujo, Veit e Moreira (2004). Assim, constatou-se a necessidade de intensificar e diversificar as alternativas didáticas para trabalhar com gráficos, buscando um melhor entendimento e aproveitamento dos estudantes.

Nesse sentido, foi realizada uma atividade com um sensor de movimento para a construção de gráficos para observar a capacidade dos estudantes em interpretar e reproduzir gráficos de movimento em tempo real ${ }^{6}$. Foi observado nessa atividade que os estudantes identificam, de modo imediato, se sua predição e/ou interpretação dos gráficos está ou não adequada.

A título de exemplificação dos gráficos construídos pelos alunos, ilustramos a seguir um conjunto de gráficos da posição versus tempo construído por um grupo da turma $\mathrm{A}$, na qual foram reunidas medidas de tempo e posição dos carrinhos, em atividade do segundo módulo didático. Esse grupo, apesar de ter obtido valores de velocidades bastante próximas, identificou a diferença existente nos gráficos. Considerando o eixo da abscissa para indicar o tempo e a ordenada para as posições, o grupo identificou que a inclinação da reta representa uma velocidade maior ou menor do carrinho usado no experimento. O grupo que construiu esses gráficos justificou a inclinação das retas:

Deu para perceber que no gráfico do carrinho com velocidade menor a reta era mais deitada e o gráfico com velocidade maior, era mais inclinada. (Grupo B).

Destacamos que os gráficos foram construídos com a mesma escala, o que possibilita a comparação entre as inclinações dos segmentos de reta, que representam as velocidades do carrinho usado pelo grupo.

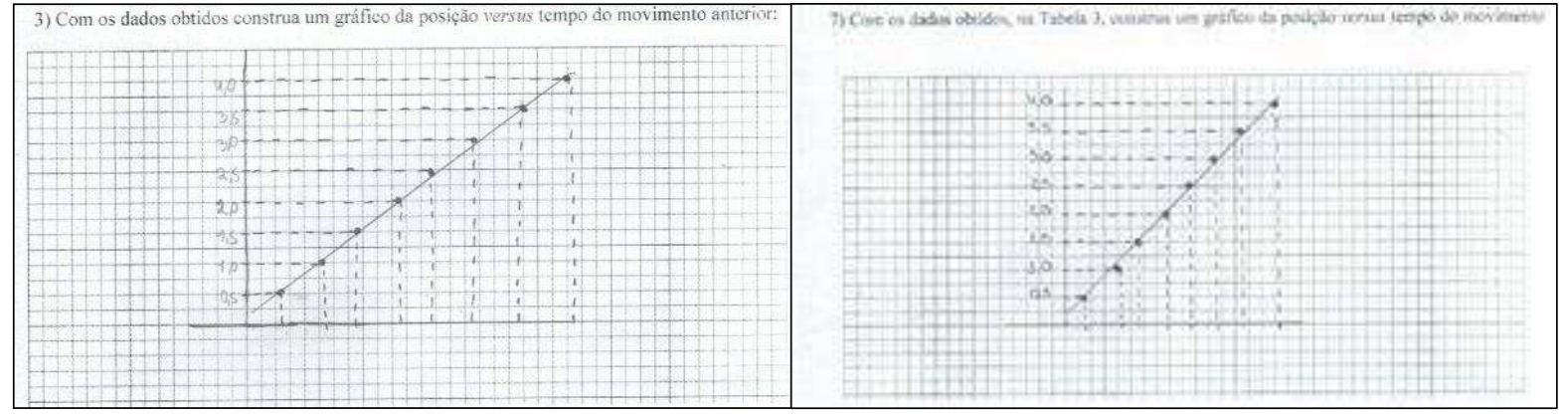

Fig. 4 - Gráficos da posição vs. tempo de velocidades diferentes dos carrinhos. Fonte: Guias respondidos pelos estudantes.

${ }^{6}$ Os resultados dessa atividade estão publicados em Dworakowski, Hartmann, Kakuno e Dorneles (2016). 


\section{Considerações finais}

Boa parte dos alunos concluiu o primeiro módulo didático compreendendo como localizar pontos no plano cartesiano e aplicar a teoria abordada em sala de aula em uma situação prática, fazendo a transposição do abstrato para o concreto (reificação de conceitos).

No segundo módulo da Unidade Didática, os alunos se engajaram de forma ativa no aprendizado de construção e interpretação de gráficos de cinemática. Nesse sentido, os alunos tiveram autonomia para variar a velocidade do carrinho via controle remoto, fizeram coleta de dados, transpondo-os para uma tabela, construíram e interpretaram gráficos da posição versus tempo e velocidade versus tempo. Além disso, os estudantes interpretaram gráficos de livros textos e reproduziram os movimentos descritos nos exercícios utilizando os carrinhos automatizados.

Ao concluir o segundo módulo didático, avalia-se que boa parte dos estudantes atingiu os objetivos de aprendizagem propostos nos quadros 2 e 3, atribuindo grande parte dos resultados alcançados à diversidade metodológica utilizada. Essa metodologia propiciou uma interatividade entre os estudantes e um engajamento ativo na realização das tarefas, o que contribuiu para o aprendizado do conteúdo de Cinemática proposto na Unidade Didática.

Após analisar a aplicação do primeiro e segundo módulos da Unidade Didática, pode-se afirmar que a atividade com o jogo batalha naval foi fundamental para ativar conhecimentos prévios dos alunos e para eles compreenderem como é feita a localização de pontos coordenados em um plano cartesiano. A atividade com o plano cartesiano no pátio da escola conduziu a uma reificação dos conceitos de reta numérica, eixos cartesianos, localização de pontos no plano e medição de distâncias entre os pontos, através da aplicação do conteúdo estudado em sala de aula em uma situação prática.

A utilização do carrinho automatizado com velocidades pré-programadas mostrouse significativa para o entendimento do processo de reunir dados sobre tempo e posição, a localização em tabelas e construção de gráficos, mas não supriu as expectativas dos autores em relação à interpretação de gráficos. Percebeu-se que no início da atividade os alunos não tinham a mínima ideia do processo de construção de gráficos da Cinemática a partir de uma situação real, mas após a realização das primeiras atividades, utilizando o carrinho, essa dificuldade foi sendo superada.

Ressalta-se, no entanto, que apesar da análise dos dados indicarem que as atividades com o carrinho com programação de velocidade pré-definida são mais adequadas para a interpretação de gráficos, isso não significa que elas devam ser usadas exclusivamente, pois o jogo batalha naval e a construção de um plano cartesiano no pátio da escola foram fundamentais para os alunos adquirirem subsunçores prévios, importantes para o processo de construção de gráficos.

Os resultados alcançados na aplicação da Unidade Didática evidenciam que a diversidade de procedimentos e ferramentas utilizadas foi fundamental para a superação de dificuldades de aprendizagem dos alunos no estudo de gráficos da Cinemática. Enfatiza-se, 
porém, que as atividades propostas nos dois módulos didáticos são complementares, não sendo indicada sua aplicação isoladamente como recurso suficiente para a consecução dos objetivos de aprendizagem propostos.

O uso de aulas expositivas permitiu a diferenciação progressiva e a reconciliação integrativa em momentos propícios. O jogo batalha naval e a representação de um sistema de coordenadas no pátio da escola propiciaram o resgate de conhecimentos prévios dos alunos e a reificação de conceitos. O emprego de tecnologias como recurso didático favoreceu a consolidação dos conhecimentos adquiridos. Acreditamos que a valorização das interações entre os alunos e entre alunos e o professor durante as atividades propostas foram decisivos para aguçar a capacidade de análise e interpretação de problemas em Cinemática.

Os resultados obtidos com a aplicação desta Unidade Didática indicam que o conjunto de atividades desenvolvidas foi potencialmente significativo para a maior parte dos alunos, sendo capaz de despertar-lhes o interesse em aprender e propiciar condições favoráveis à aprendizagem do significado das representações gráficas de posição, velocidade e tempo de objetos móveis em Cinemática. Tendo sido aplicada e validada no Ensino Médio, a Unidade Didática descrita neste trabalho é potencialmente adequada, também, para a introdução ao ensino de gráficos em aulas de Ciências e/ou Matemática do Ensino Fundamental. Essa afirmação, contudo, necessita de validação através de pesquisa.

\section{Referências}

ARAUJO, I. S.; VEIT, E. A.; MOREIRA, M. A. Atividades de modelagem computacional no auxílio à interpretação de gráficos da Cinemática. Revista Brasileira de Ensino de Física, São Paulo, v. 26, n. 2, p. 179-184, 2004.

ARDUINO. Disponível em: <http://www.arduino.cc/>. Acesso em: 01 jul. 2015.

BRASIL, SEMT. Parâmetros Curriculares Nacionais (Ensino Médio): Parte III - Ciências da Natureza, Matemática e suas Tecnologias, 2000.

DORNELES, P. F. T.; VEIT, E. A.; MOREIRA, M. A. Ganhos na aprendizagem de conceitos físicos envolvidos em circuitos elétricos por usuários da ferramenta computacional modellus. In: ENCONTRO NACIONAL DE PESQUISA EM EDUCAÇÃO EM CIÊNCIAS, V, 2005, Bauru. Atas... Disponível em: <http://www.nutes.ufrj.br/abrapec/venpec/conteudo/artigos /3/pdf /p174.pdf>. Acesso em: 23 set. 2017.

DWORAKOWSKI, L. A. Construção e interpretação de gráficos da cinemática: Uma proposta para o ensino médio politécnico. 2015. 114 f. Dissertação (Mestrado Profissional em Ensino de Ciências) - Universidade Federal do Pampa, Bagé.

DWORAKOWSKI, L. A.; HARTMANN, A. M.; KAKUNO, E. M.; DORNELES, P. F.T. Uso da plataforma Arduino e do software PLX-DAQ para construção de gráficos de movi- 
mento em tempo real. Revista Brasileira de Ensino de Física, São Paulo, v. 38, n. 3, e3503, jun. 2016.

MOREIRA, M. A.; SILVEIRA, F. L. Instrumento de pesquisa em ensino e aprendizagem: a entrevista clínica e a validação de testes de papel e lápis. Porto Alegre: EDIPUCRS, 1993. $101 \mathrm{p}$.

MOREIRA, M. A. Teorias de aprendizagem. 2. ed. São Paulo: EPU, 2011.

PRESCOTT, S. P. P.; ALVES, J. C. F.; SILVA, M. S. R.; ROCHA, M. N. R. Programa de Melhoria e Expansão do Ensino Médio - PROMED. Rio de Janeiro, UFRJ, 2005. Disponível em: <http://www.ccmn.ufrj.br/curso/trabalhos/pdf/matematicatrabalhos/conceitos _tecnologias_algebra/c-t-numeros>. Acesso em: 24 abr. 2013.

RIO GRANDE DO SUL, SEDUC-RS. Proposta Pedagógica para o Ensino Médio Politécnico e Educação Profissional Integrada ao Ensino Médio - 2011-2014. Porto Alegre, 2011.

ROQUE, R. R.; PEREIRA, P. S. Da atividade ao conceito de Plano Cartesiano: Uma vivência na escola. In: ESCOLA DE INVERNO DE EDUCAÇÃO MATEMÁTICA, III, 2012, Santa Maria. Anais... v. 1, n. 1, 2012.

VEIT, E. A.; ARAÚJO, I. S. Tecnologias de Informação e Comunicação: Facilitando a Aprendizagem Significativa de Ciências e Matemática. Porto Alegre, IF - UFRGS, 2006.

WRASSE, A.; SANTOS, R.; TONEL, A. P.; KAKUNO, E. M.; DORNELES, P. Carrinho Automatizado como recurso facilitador na construção e interpretação de gráficos da Cinemática. In: SIMPÓSIO NACIONAL DE ENSINO DE FÍSICA, XX, 2013, São Paulo. Atas...

(cc) EY-NC-ND Direito autoral e licença de uso: Este artigo está licenciado sob uma Licença Creative Commons. 